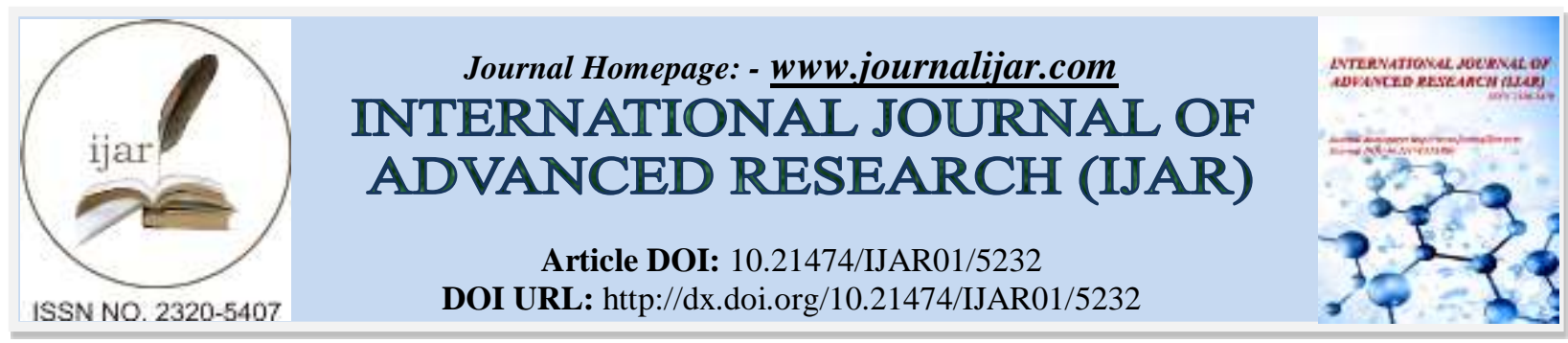

RESEARCH ARTICLE

\title{
MAIN CONSIDERATIONS AND CURRENT TECHNOLOGICAL ADVANCES ON THE CAD / CAM SYSTEM: A BRIEF REVIEW.
}

\section{Andressa Rocha Codogno ${ }^{1}$, Amanda Rocha ${ }^{1}$, Mailton Neves de Oliveira ${ }^{1}$, Idiberto José Zotarelli Filho ${ }^{2}$ and Vanda Rieko Fujita Myazaki ${ }^{1,2}$}

1. University Center North Paulista (Unorp) - São José do Rio Preto - SP, Brazil.

2. Post graduate and continuing education (Unipos), Street Ipiranga, 3460, São José do Rio Preto SP, Brazil 15020-040.

\section{Manuscript Info}

Manuscript History

Received: 21 June 2017

Final Accepted: 23 July 2017

Published: August 2017

Key words:-

Dental Implant, CAD / CAM System,

Dental Prosthesis, Clinical Research.

\section{Abstract}

Introduction: The CAD / CAM system was introduced in dentistry with the purpose of promoting the manufacture of prostheses based on a three-dimensional system of last generation. The CAD / CAM system consists of the intraoral scanner or the plaster model such as CAD, while the CAM is the milling machine. One of the main objectives of this technology is the simplification and optimization in the production of prosthetic structures, aiming at the production of structures with a high standard of quality and aesthetics, in a personalized and planned way with digital precision. Objective: to present the main benefits of the CAD / CAM system for the creation of dental prostheses, making a historical search and show its importance in contemporary dentistry. Methods: Experimental and clinical studies were included (case reports, retrospective, prospective and randomized trials) with qualitative and / or quantitative analysis. The words were included "Dental Prostheses" and "CAD / CAM system". Conclusion: Technological evolution has transformed something considered to be handcrafted in an automated, exact production with superior quality level, reducing the time of product preparation, eliminating costs of steps, extinguishing manual errors, thus allowing a better job, where To work with extremely durable materials.

Copy Right, IJAR, 2017,. All rights reserved.

\section{Introduction:-}

The CAD / CAM system was introduced in dentistry with the purpose of promoting the manufacture of prostheses based on a last generation three-dimensional system [1-3]. Where the search for aesthetic solutions has been increasingly challenging, given the patient's demand and the growing number of techniques and materials available for protective rehabilitation. It aims at the resistance of the material being the primary factor to determine the indication of the technique as well as the preservation of rehabilitation over time and the need for movements that lead to the possibility of performing rehabilitations of larger extensions [1,2].

The CAD / CAM system consists of the intraoral scanner or the plaster model such as CAD, while the CAM is the milling machine, that is, the design of a prosthetic structure in a computer (Computer Aided Design) followed by its A milling machine $[3,4]$. 
Several ceramic systems are available in the market, making professionals in the area require constant recycling according to their properties and indications [5]. Most used are, ceramic are the main alternative restorative material for dental structure due to its favorable properties, such as: compressive strength, thermal conductivity, similarity to dental tissues, radiopacity, marginal integrity and color stability [5,6 ].

One of the main objectives of this technology is the simplification and optimization in the production of prosthetic structures, aiming at the production of structures with high quality and aesthetics, in a personalized and planned way with digital precision [3-6]. With the advancement of technology and dental innovations, perfecting digital printing systems, we need to know if these systems achieve the same levels of precision as conventional printing techniques. It is undeniable that modern dentistry has sought treatment methods that increasingly combine esthetics, durability, ease of execution and time savings, both for the professional and for the patient $[6,7]$.

The technological progress that occurs in diverse fields of science applies to the dental area and has collaborated in the development [8]. And it is of fundamental importance to seek the correct indication of the materials through clinical needs, knowing their advantages and disadvantages presented by each of the systems [9].

The present work aimed to present the main benefits of the CAD / CAM system for the creation of dental prostheses, making a historical search and show its importance in contemporary dentistry.

\section{Methods:-}

Experimental and clinical studies were included (case reports, retrospective, prospective and randomized trials) with qualitative and / or quantitative analysis. Initially, the key words were determined by searching the DeCS tool (Descriptors in PubMed, Health Sciences, BIREME base) and later verified and validated by MeSh system (Medical Subject Headings, the US National Library of Medicine) in order to achieve consistent search.

\section{Mesh Terms:-}

The words were included "Dental Implant", "CAD / CAM system" and "Dental Prostheses". The literature search was conducted through online databases: Pubmed, Periodicos.com and Google Scholar. It was stipulated deadline, and the related search covering all available literature on virtual libraries.

\section{Series of Articles And Eligibility:-}

A total of 40 articles were found involving CAD / CAM system. Initially, it was held the exclusion existing title and duplications in accordance with the interest described this work. After this process, the summaries were evaluated and a new exclusion was held. A total of 25 articles were evaluated in full, and 14 were included and discussed in this study.

\section{Literary Results and Discussion:- What is CAD / CAM?}

CAD: Computer Aided Design. CAM: Computer Aided Manufacturing [1]. It is a computational system used to aid in product development and manufacturing stages. CAD is a graphical software used in engineering to create twodimensional drawings (2D) or three-dimensional (3D) models of products [2-5]. Helps in the development stages. It can be applied in several segments: Civil Engineering, Electrical, Mechanics; Architecture; Dentistry, among others. A classification of CAD systems assists in the choice of a specific platform for each occasion [6].

The CAM software uses geometry created in CAD and generates CNC (Computer Numerical Command) programs of different operations (turning, milling, drilling, laser cutting) assisting in the manufacturing step [4,5].

\section{Historic:-}

The first applications of CAD / CAM to assist engineering steps began in the 1950s in the USA; Were limited to 2D geometry. It had its introduction in Dentistry in the late 70's and early 80's marking a new generation of CAD systems - the development of computational techniques for the representation of three-dimensional objects [3-5].

In particular, three people contributed to the development of the CAD / CAM system in Dentistry: Dr. Duret, Dr. Moermann and Dr. Anderson. The first to use the system was Dr. Duret. In 1971 he began to manufacture crowns in a functional way using several systems [6,7]. Later, Dr. Moermann, precursor of the CEREC@ system, used new 
technology in the patient's office, which allowed the completion of the work in a single day. Finally, in the 1980s, Dr. Anderson, who developed POCERA®, manufactured copings, introducing CAD / CAM technology for veneer composite processes. In 1990, he directly applied the system for the production of crowns and prostheses, reproducing a 3D image using computer graphics and projecting the virtual image on a monitor [6-8].

In the last 25 years, new systems have been developed and are available in the market [8].

The digitalization (technological innovation) of images, result in significant changes in prosthetics and prosthetic infrastructures. This technology brings an evolution in the dental area, with the main objective of optimizing the production [9]. The program suggests the result from a database, dental anatomy or the correlation technique, taking into account images obtained before preparation by the optical impression of the occlusal surface of the teeth as well as antagonistic teeth [10].

Today CAD / CAM technology has been used in the production of partial restorations such as, inlays, onlays, partial or total anatomical crowns, provisional, bridges and facets [1,2]. It is also applied to implant techniques as a surgical guide, allowing the transfer of software planning to the surgical field. The manufacture of total dentures is still limited [1].

Materials used for milling prosthetic structures are pre-fabricated blocks or discs of the following materials: leucitereinforced glass ceramics, glass-reinforced alumina, densely synthesized alumina, Y-TZP (zirconia with partial or total sintering, titanium, alloys Precious, non-precious alloys and reinforced strength acrylic [2].

There are three different concepts of production: as to its location: Chairside Production; Inlab Production; Production in production centers, exemplified below:

\section{Chairside Production:-}

All CAD / CAM components are located in the dental office, without laboratory involvement [1]. An intraoral camera or scanner (scan tool) transforms a real geometry into digital data that will be processed by the computer. Where the software transforms the data set into the desired product [1]. It replaces conventional printing (molding), saving time and providing patients with short-term restorations [2].

\section{Inlab Production:-}

Equivalent to the traditional sequence between the dentist and the prosthetic laboratory. The dentist sends the impression (molding) to the laboratory where the model is manufactured [2]. Production using the CAD / CAM is done in the laboratory and thereafter returns to the dental clinic [2].

\section{Production in production centers:-}

The dental office scanner or prosthetic laboratory is connected via the Internet and sends data to the production facility, which manufactures the finished product in the CAD / CAM and sends it to the office or laboratory [3]. The advantage is the low investment, because only the scanner and the software are acquired. It was found that ceramics of zirconium oxides have interesting aesthetic, physical and mechanical properties and that therefore they can substitute metal-ceramic restorations with some care, respecting the limitations of the system $[13,14]$.

Although conventional printing materials have great accuracy, they have some disadvantages, such as discomfort for the patient, cause a lot of dirt, have several steps that allow greater risk of imperfections, and require more professional experience [4]. The digital printing system offers a printing method that minimizes these disadvantages, as well as having great precision, are more comfortable for patients, more agile, easier to use, do not cause dirt and eliminate several clinical and laboratory steps that could Cause production errors [13,14].

\section{Conflict of interests:-}

There is no conflict of interest between authors.

\section{Conclusion:-}

Technological evolution has transformed something considered to be an artisan in an automated production, exact and with a superior quality level, reducing the time of product preparation, eliminating costs of steps, extinguishing manual errors, thus enabling a better job, where it allows the professional to work With ease in extremely resistant materials. 


\section{References:-}

1. Spies BC, Pieralli S, Vach K, Kohal R-J. CAD/CAM-fabricated ceramic implant-supported single crowns made from lithium disilicate: Final results of a 5-year prospective cohort study. Clin Implant Dent Relat Res. 2017; 00:1-8. https://doi.org/10.1111/cid.12508.

2. Sheridan RR, Verrett R, Haney S, Schoolfield J. Effect of Split-File Digital Workflow on Crown Margin Adaptation. J Prosthodont. 2017 Jun 9. doi: 10.1111/jopr.12606.

3. Christensen GJ: In-office CAD/CAM milling of restorations: the

4. future? J Am Dent Assoc 2008;139:83-85

5. Christensen GJ: In-office $\mathrm{CAD} / \mathrm{CAM}$ milling of restorations: the

6. future? J Am Dent Assoc 2008;139:83-85

7. Christensen GJ: In-office CAD/CAM milling of restorations: the

8. future? J Am Dent Assoc 2008;139:83-85

9. Christensen GJ: In-office CAD/CAM milling of restorations: the

10. future? J Am Dent Assoc 2008;139:83-85

11. Christensen GJ: In-office CAD/CAM milling of restorations: the future? J Am Dent Assoc 2008;139:83-85.

12. Trost L, Stines S, Burt L: Making informed decisions about incorporating a CAD/CAM system into dental practice. J Am Dent Assoc 2006;137:32S-36S.

13. Batson ER, Cooper LF, Duqum I, et al: Clinical outcomes of three different crown systems with CAD/CAM technology. J Prosthet Dent 2014;112:770-777.

14. Tamac E, Toksavul S, Toman M: Clinical marginal and internal adaptation of CAD/CAM milling, laser sintering, and cast metal ceramic crowns. J Prosthet Dent 2014;112:909-913.

15. Euan R: Marginal adaptation of zirconium dioxide copings: Influence of the CAD/CAM system and the finish line design. J Prosthet Dent 2014;16:1-8.

16. Buchi DL, Ebler S, H " ammerle CHF, et al: Marginal and internal " fit of curved anterior CAD/CAM-milled zirconia fixed dental prostheses: an in-vitro study. Quintessence Int 2014;45:837-846.

17. Anadioti E, Aquilino SA, Gratton DG, et al: 3D and 2D marginal fit of pressed and CAD/CAM lithium disilicate crowns made from digital and conventional impressions. J Prosthodont 2014;23:610-617.

18. Patzelt SB, Spies BC, Kohal RJ. CAD/CAM-fabricated implantsupported restorations: a systematic review. Clin Oral Implants Res. 2015;26(suppl 11):77-85.

19. Van Noort R. The future of dental devices is digital. Dent Mater. 2012;28:3-12.

20. Guess PC, Zavanelli RA, Silva NR, Bonfante EA, Coelho PG, Thompson VP. Monolithic CAD/CAM lithium disilicate versus veneered YTzp crowns: comparison of failure modes and reliability after fatigue. Int $\mathbf{J}$ Prosthodont. 2010;23:434-442.

21. Cooper LF, Stanford C, Feine J, McGuire M. Prospective assessment of CAD/CAM zirconia abutment and lithium disilicate crown restorations: 2.4 year results. J Prosthet Dent. 2016;116:33-39.

22. Lawson NC, Bansal R, Burgess JO. Wear, strength, modulus and hardness of CAD/CAM restorative materials. Dent Mater. 2016;32: 275-283. 